\title{
Simulando a dinâmica populacional de uma colmeia para o ensino de Biologia
}

\author{
Title: Simulating the population dynamics of a hive for teaching Biology \\ José Eduardo Mendes de Figueiredo \\ UERJ - Universidade do Estado do Rio de Janeiro \\ Rio de Janeiro - RJ \\ profedu@oi.com.br \\ Rosa Maria E. Moreira da Costa \\ UERJ - Universidade do Estado do Rio de Janeiro \\ Rio de Janeiro - RJ \\ rcosta@ime.uerj.br
}

Vera Maria Benjamim Werneck

UERJ - Universidade do Estado do Rio de Janeiro

Rio de Janeiro - RJ

vera@ime.uerj.br

\begin{abstract}
Resumo Este trabalho apresenta um ambiente de simulação das atividades de uma colmeia para o ensino de Biologia. As variáveis do sistema podem ser alteradas visando analisar os diferentes parâmetros envolvidos no desenvolvimento e manutenção de uma colmeia, tais como, o clima, duração e tempo da florada de diferentes plantas, ventos e umidade do ar. Para controlar a combinação desses diferentes itens, foram explorados conceitos de multiagentes em Inteligência Artificial Distribuída. O sistema apresenta possibilidades de visualizações gráficas para apoiar o entendimento dos fenômenos associados a este tema.
\end{abstract}

Palavras-Chave: Simulação, multiagentes, colônia de abelhas, ambiente de aprendizagem.

\begin{abstract}
This paper presents an environment that simulates the activities of a hive to support the Biology learning. The system variables can be changed in order to analyze the different parameters involved in the development and maintenance of a hive, such as weather, time and flowering of different plants, winds and humidity. For controlling the combination of these items we explored the concepts of multi-agent in Distributed Artificial Intelligence. The system presents possibilities for graphical visualizations to support the understanding of the phenomena associated with this topic
\end{abstract}

Keywords: Simulation, multi-agents, bee colony, learning environment. 


\section{Introdução}

O ensino de Biologia tem utilizado novos ambientes educacionais digitais como forma de estimular e melhorar o processo de aprendizado. Esta tendência visa mudar o modelo vigente, no qual os alunos memorizam conceitos e se desestimulam, considerando as aulas monótonas [1]. Neste contexto destaca-se como importante ferramenta o uso de simulações computacionais. Elas permitem que os alunos observem o comportamento de um sistema e tirem suas conclusões, através da alteração de parâmetros e da análise de novos comportamentos que surgem [2]. Os professores podem sugerir determinadas configurações iniciais para que os alunos interpretem as diferentes respostas mostradas pelo ambiente. Este processo permite ao aluno refinar os conceitos adquiridos [3].

Assim, as simulações favorecem uma ativa participação do aluno no processo de aprendizagem. Sua associação com um ambiente gráfico e colorido torna o processo de aprendizagem de uma disciplina mais atrativo [4]. O resultado das simulações pode ainda, ser analisado do ponto de vista numérico, como por exemplo, a avaliação da curva de crescimento de populações.

No ensino de Biologia são muitos os fenômenos que podem ser simulados, entre eles estão o processo de divisão celular [4] e a relação presa-predador [5]. Outra possibilidade de simulação do mundo real em um sistema digital é reproduzir as atividades de insetos sociais. Neste caso, vários agentes, os insetos, agem conforme sua experiência e interagem com outros agentes, tomando decisões com o objetivo de manter a unidade do grupo. Estes grupos constituem um Swarm ou enxame [6].

Em geral, o estudo do comportamento dessas colônias é complexo de ser entendido, observado e estudado. Logo, a criação de uma simulação que explore variáveis reais e que mostre a evolução de colônias de insetos submetidos a diferentes condições climáticas ampliaria as possibilidades do processo de ensino-aprendizagem dos conceitos associados.

O nível de complexidade envolvido no estudo desse tema induz a busca de tecnologias que possam ser integradas, visando alcançar uma maior exatidão nos resultados. A área de Inteligência Artificial Distribuída (IAD) dá uma grande contribuição para o desenvolvimento destes sistemas, pois estuda os mecanismos de interação de entidades computacionais, através da cooperação, com um objetivo comum. Nesta área, se destacam os Sistemas Multiagentes (SMA) que podem ajudar a simular ambientes de insetos sociais, pois criam uma estrutura de autonomia e cooperação semelhante às observadas nos grupos de insetos sociais. A distribuição do trabalho entre os agentes se assemelha às encontradas em colmeias, por exemplo.

Este artigo tem por objetivo apresentar um ambiente de simulação e aprendizagem, inserido na área de Biolo- gia, para o estudo do comportamento de uma sociedade de abelhas. A solução adotada explorou técnicas de Inteligência Artificial (IA), tais como Swarm e SMA, com visualização dos resultados através de gráficos. O ambiente de simulação permite a configuração de diferentes variáveis envolvidas no processo de desenvolvimento da colméia, tais como: Intensidade de chuva, umidade do ar, velocidade do vento e recursos florais (néctar e pólen). Os resultados podem ser analisados conforme as variáveis do ambiente são alteradas.

Para atingir este objetivo, este trabalho está estruturado da seguinte forma: a seção 2 apresenta a importância das simulações no processo ensino-aprendizagem; a seção 3 analisa alguns ambientes de simulação; a seção 4 discute aspectos da área de Inteligência Artificial utilizadas no desenvolvimento de simulações; a seção 5 mostra a especificação e a modelagem do protótipo; a seção 6 apresenta o protótipo do SIM-Colmeia com suas interfaces de usuário; na seção 7 são apresentados resultados iniciais de testes realizados com o sistema e finalmente, a seção 8, tece conclusões sobre este trabalho e apresenta perspectivas futuras.

\section{Informática e educação}

A crescente disseminação da informatização provoca mudanças que atingem todos os níveis da sociedade, produzindo alterações nos diversos sistemas existentes, que vão das novas formas de consumo até novas formas de aprender. Isto tem gerado debates e experiências sobre como integrá-la no processo educativo [7].

Neste sentido, de acordo com Lazzaroto et al. [8], o uso da Informática na educação só se tornará eficaz se o computador e as redes forem as ferramentas centrais da interação entre todos os envolvidos no processo de aprendizagem: aluno, professor e conteúdo.

As ferramentas computacionais permitem a alunos e professores analisar mundos artificiais criando ambientes de ensino e aprendizagem com grande possibilidade investigativa [5]. Neste contexto, as simulações digitais são sistemas que buscam recriar um ambiente real, com todas as suas variáveis, em um cenário computacional. As simulações podem ser amplamente utilizadas em ambientes educacionais, pois permitem ao aluno interagir diretamente com as variáveis de diferentes sistemas e analisar as diferentes respostas retornadas pelo modelo que está sendo simulado.

O papel do professor, condutor do ensinoaprendizagem, é fundamental nesse processo. Ele deve lançar os estímulos, desafios, instigando os alunos a realizarem as simulações, alterando os dados de entrada e, interativamente, desenvolvendo testes de hipóteses, construindo novos conhecimento e assegurando a sequência do fenômeno em estudo [9]. 
Complementando o potencial das simulações, as animações possuem a capacidade de passar informações visuais aos alunos, que podem também considerar mudanças temporais. Isto é uma vantagem em relação às imagens estáticas e que se repetem independente da passagem do tempo [10]. Apesar de todos os aspectos positivos, alguns cuidados devem ser tomados visando evitar o excesso de informações que por sua vez, possam causar um desvio de atenção do foco principal do estudo [11].

Neste sentido, as animações devem manter uma relação entre as mudanças ao longo do tempo e as informações conceituais que devem ser trabalhadas. Além disso, elas devem ser lentas o suficiente para que permitam ao observador perceber as mudanças que ocorrem. Elas são mais interessantes para fenômenos contínuos do que para descrever fenômenos discretos [12].

Dessa forma, um ambiente de aprendizagem computacional precisa disponibilizar ferramentas ao professor para que este conduza o processo de aquisição de conhecimento de seu aluno numa abordagem interacionista. Deve ainda, permitir a formulação de hipóteses e a possibilidade de testá-las, com o intuito de possibilitar ao aluno a criação de suas visões do objeto de estudo, extraindo novos conhecimentos e conclusões [5].

Em geral, nas disciplinas de Física e Matemática, são encontradas várias ferramentas que buscam simular fenômenos e modelos relativos aos conteúdos curriculares do ensino fundamental e médio [13], [14], [15]. Contudo, especificamente na área de Biologia, alvo deste trabalho, são encontradas poucas ferramentas computacionais que oferecem ao aluno possibilidades de interagir, alterar parâmetros, testar hipóteses, estudar modelos 3D ou atuar em um mesmo ambiente de simulação que utilize dados reais, tornando essa experiência mais próxima do que acontece no mundo real.

Com vistas a ilustrar esta discussão, a seguir, são apresentados alguns ambientes de simulação para a área de Biologia.

\section{Ambientes de simulação}

Alguns ambientes de simulação para aprendizagem, que exploram conceitos da biologia podem ser encontrados na literatura, e serão descritos brevemente a seguir.

O ambiente STELLA- Structural Thinking Experimental Learning Laboratory with Animation - é uma ferramenta de modelagem quantitativa e semiquantitativa de sistemas complexos associados à Física, Química e Biologia, que usa objetos como tanques, válvulas, conversores e conectores e permite a construção de modelos matemáticos pela simples conexão de ícones. As equações são automaticamente geradas para o modelo. Para a construção do modelo e posterior simulação é necessário que os alunos encontrem as variáveis relevantes do sis- tema em questão. O ambiente de modelagem se encarrega de mostrar a evolução temporal do fenômeno [16].

O Instituto de Química da Universidade do Rio Grande do Sul desenvolveu um ambiente de simulação ambiental, o Carbópolis [17]. Nele os alunos avaliam a diminuição da atividade agropecuária próximo a uma usina termelétrica. O estudante lê depoimentos, analisa medições ambientais, cria relatórios e hipóteses para as causas do problema e possíveis soluções. Há ainda uma biblioteca com textos que podem ser consultados pelo aluno para esclarecimento de algum aspecto.

WebBeePop foi desenvolvido por Carl Hayden Bee Research Center, pertencente ao United States Department of Agriculture's Agricultural Research Service, para simulação da dinâmica populacional e sua dependência dos fatores climáticos. A interatividade é baixa e a interface gráfica limitada à entrada e saída de dados numéricos e os dados climáticos são reais [18].

O PhET [13] é um ambiente web que possui várias simulações para a área de Física e Química. São simulações criadas em Java e Flash com licença GNU. As simulações possuem interface gráfica, boa usabilidade e não utilizam RV ou IA. Na área de Biologia, existem simulações para o conteúdo de citologia e ecologia. O site oferece junto com a simulação muitas ideias para condução de aulas. A simulação na área de seleção natural é focada na relação presa-predador entre coelhos e lobos, através de algumas gerações. $\mathrm{O}$ ambiente explora os gráficos para exibir este crescimento populacional.

O Hares \& Lynx Model é um applet apoiado no NetLogo [19], que é um ambiente de modelagem computacional para sistemas multiagentes. O Hares \& Lynx Model consiste de uma simulação da relação presapredador existente entre os linces e as lebres. Possui um ambiente gráfico onde os valores iniciais são inseridos e uma janela onde se pode ver uma animação simples da evolução das populações. Há ainda uma janela que mostra o gráfico da curva de crescimento das duas espécies.

O Cell Biology [20] é um ambiente Web desenvolvido em Flash que apresenta várias animações que simulam conteúdos de Biologia celular. As animações possuem ambientação gráfica e baixa interatividade com o usuário. Possui uma versão em português. Não possui alteração de parâmetros iniciais.

Visando perceber as diferentes abordagens e funcionalidades dos sistemas acima apresentados, a Tabela 1 apresenta um resumo das principais características de cada um desses sistemas.

Como pode ser observado na Tabela 1 , os sistemas em geral, possuem um nível de interação de médio a baixo, baixo índice de uso de estratégias inteligentes, e nenhum dos sistemas pesquisados explora o potencial das tecnologias de Realidade Virtual. Não foi possível identificar nenhum tipo de integração de tecnologias que pos- 
sibilitasse um aumento do potencial de simulação desses ambientes.
Entretanto, um ponto comum a todos é a área de aplicação, Biologia, ressaltando a importância das simulações neste domínio.

\begin{tabular}{|c|c|c|c|c|c|c|}
\hline & STELLA & CARBÓPOLIS & WebBeePop & PhET & $\begin{array}{c}\text { Hares \& Lynx } \\
\text { Model }\end{array}$ & Cell Biology \\
\hline Objetivo & $\begin{array}{l}\text { Simular situações } \\
\text { em sistemas } \\
\text { químicosbiológi- } \\
\text { cos e físicos }\end{array}$ & $\begin{array}{c}\text { Discutir o } \\
\text { problema da } \\
\text { poluição ambi- } \\
\text { ental }\end{array}$ & $\begin{array}{c}\text { Simular cresci- } \\
\text { mento populacio- } \\
\text { nal de abelhas e as } \\
\text { variáveis climáti- } \\
\text { cas }\end{array}$ & $\begin{array}{l}\text { Simular ambi- } \\
\text { entes para } \\
\text { utilização em } \\
\text { contexto educa- } \\
\text { cional }\end{array}$ & $\begin{array}{l}\text { Simular a } \\
\text { relação presa- } \\
\text { predador entre } \\
\text { linces e lebres. }\end{array}$ & $\begin{array}{c}\text { Visualizar } \\
\text { animações } \\
\text { sobre Biolo- } \\
\text { gia Celular }\end{array}$ \\
\hline Domínio & Física e Biologia & $\begin{array}{l}\text { Biologia e } \\
\text { Química }\end{array}$ & Biologia & $\begin{array}{c}\text { Física, Química, } \\
\text { Biologia e } \\
\text { Matemática }\end{array}$ & Biologia & Biologia \\
\hline Agentes & Não & Não & Não & Não & Sim & Não \\
\hline Linguagem & Delphi & Java & Java & Java e Flash & Java & Flash \\
\hline $\begin{array}{l}\text { Interface } \\
\text { Gráfica }\end{array}$ & $\begin{array}{c}\text { Manipulação } \\
\text { direta de ícones }\end{array}$ & $\begin{array}{c}\text { Gráfica Interati- } \\
\text { va }\end{array}$ & Gráfica & $\begin{array}{c}\text { Gráfica Interati- } \\
\text { va }\end{array}$ & $\begin{array}{c}\text { Gráfica Interati- } \\
\text { va }\end{array}$ & Gráfica \\
\hline $\begin{array}{c}\text { Grau de } \\
\text { interação }\end{array}$ & Médio & Médio & Baixo & Médio & Baixo & Baixo \\
\hline $\begin{array}{c}\text { Inteligência } \\
\text { Artificial }\end{array}$ & Não & Não & Não determinado & Não & $\begin{array}{l}\text { Inteligência } \\
\text { Distribuída }\end{array}$ & Não \\
\hline $\begin{array}{c}\text { Realidade } \\
\text { Virtual }\end{array}$ & Não & Não & Não & Não & Não & Não \\
\hline
\end{tabular}

Tabela 1 : Comparativo entre ambientes de simulação

\section{$4 O$ uso de estratégias inteligentes nas simulações}

A Inteligência Artificial (IA) é uma área da Ciência da Computação que busca criar sistemas computacionais que possam resolver problemas, raciocinar sobre fatos, compreender linguagens, simular um especialista, etc. $\mathrm{O}$ trabalho em IA tem sido incessante nos últimos anos na busca por sistemas que possam resolver problemas sem a intervenção dos seres humanos, isto é, simulando a capacidade humana de raciocinar e tomar decisões. Um especial interesse tem sido dado à resolução de problemas envolvendo Swarm Intelligence.

Swarm Intelligence utiliza métodos baseados em populações, no qual o comportamento coletivo de indivíduos simples surge das interações entre eles e com o ambiente. Em outra definição, Swarm pode ser entendido como a área que lida com sistemas artificiais compostos de muitos indivíduos que atuam usando controle descentralizado e auto-organização [21].

Estes sistemas podem ser observados na natureza em sistemas de partículas ou colônias de insetos sociais, tais como formigas ou abelhas. Em colônias de abelhas há uma divisão do trabalho, no qual se destaca o trabalho da abelha campeira. Ela parte em busca de um campo de flores para extrair néctar e pólen e retorna na tentativa de aliciar outras abelhas a segui-la. Não há um comando centralizado neste processo e existe uma interação entre a abelha, o meio no qual está inserida e as outras abelhas. A atividade de cada indivíduo, segundo a sua experiência e a troca de informações, levam ao objetivo maior, isto é, manter a integridade física e a evolução da colmeia.

A Inteligência Artificial Distribuída (IAD) através da abordagem de multiagentes (SMA) contribui para a simulação destes ambientes colaborativos e descentralizados. Entende-se como agente uma entidade computacional que é capaz de perceber mudanças no meio através de sensores e agir através de atuadores. Os agentes no SMA são entidades autônomas que agem, se comunicam e tomam decisões no ambiente em que estão inseridos. A capacidade de resolução cooperativa nestes ambientes é uma das principais características.

A seguir, o ambiente Sim-Colmeia, que segue as abordagens das simulações inteligentes, é descrito sucintamente.

\section{Especificação do SIM-Colmeia}

O sistema SIM-Colmeia tem por objetivo disponibilizar um ambiente de simulação para o estudo do comportamento de uma colmeia, utilizando técnicas de Inteligência Artificial, principalmente, como apoio às aulas de Biologia, além de possibilitar interatividade e o uso tanto no ensino médio quanto no ensino fundamental.

O processo de desenvolvimento do ambiente envolveu um esforço de pesquisa e estudo tanto no aspecto técnico da implementação, quanto nos aspectos teóricos 
da modelagem e do domínio do conhecimento das atividades das abelhas. Para isso, foi necessário utilizar ferramentas variadas a fim de que os requisitos fossem alcançados. O ponto de partida foi o trabalho de graduação de André Silva [22] que modelou a busca por recursos florais de uma abelha. Ele utilizou a Metodologia MaSE (Multi-Agent System Engineering) [23], por ser uma metodologia que utiliza conceitos de UML sendo, por isso, a mesma metodologia utilizada na modelagem dos agentes deste trabalho.

Para definição dos requisitos do Sim-Colmeia foi necessário descrever as premissas e domínio do sistema através da identificação das bases curriculares para os conteúdos explorados e da descrição da vida em uma sociedade de abelhas. A partir dessas informações, foram identificados os requisitos do SIM-Colmeia, foram realizadas a modelagem dos agentes, a modelagem do ambiente de Realidade Virtual e a modelagem matemática da simulação.

\subsection{Domínio}

O domínio deste trabalho é a área de Biologia, mais especificamente o ensino de Ecologia no ensino médio e fundamental. Ele explora o crescimento populacional de uma sociedade de abelhas e o balanço energético que as mantêm vivas.

As abelhas são insetos conhecidos há mais de $40 \mathrm{mil}$ anos. Elas estão distribuídas por vários continentes. O manejo de seus produtos já era feito por gregos e egípcios desde 2400 a.C. Elas fazem parte da ordem dos himenópteros. São conhecidas por volta de 20 mil espécies diferentes de abelhas [24].

As abelhas são consideradas insetos sociais, isto é, possuem uma organização em castas e cada indivíduo possui um papel na coletividade. Basicamente, as abelhas apresentam três tipos de indivíduos: rainha, zangões e operárias, cada um com seus papéis bem definidos dentro da sociedade [24].

A abelha rainha é responsável pela postura diária de ovos e produção de substâncias inibidoras que evitam que outras abelhas se desenvolvam até a fase de rainha. Isto garante a existência de apenas uma abelha rainha na colmeia. Em colmeias com rainhas velhas, podem coexistir durante algum tempo duas rainhas. Elas podem colocar até 2000 ovos por dia [25].

Os zangões são machos que possuem função reprodutiva. Eles são responsáveis pela fecundação da rainha, função na qual são bastante eficientes, morrendo em seguida [24].

As abelhas operárias são fêmeas estéreis. Elas desempenham várias atividades que visam manter o equilíbrio e o desenvolvimento da colmeia [26]:

- Limpeza da colmeia;

- Busca de néctar, pólen e água;
- Produção de mel, própolis e de cera com a qual constróem os favos;

- Defesa da colmeia;

- Alimentação da rainha, dos zangões e das larvas; As funções acima são desempenhadas conforme a idade da operária, culminando com a coleta de néctar e pólen. Geralmente, vivem em média 40 dias. Quando estão coletando nutrientes, as abelhas operárias são conhecidas como campeiras ou forrageiras e assim permanecem até a sua morte. A atividade forrageira é de extrema importância para a colmeia, pois fornece a energia necessária para a manutenção do equilíbrio total e a possibilidade de crescimento da população. Além disso, é a partir do material coletado que são produzidas substâncias importantes, como a cera e o mel.

Como visto anteriormente, a abelha rainha realiza a postura de ovos diariamente. Os ovos eclodem originando as larvas que são alimentadas pelas operárias. As larvas passam a fase de pupa e não são mais alimentadas até a eclosão [27]. A diferenciação entre rainha, operária e zangão é feita pela fecundação ou não do ovo, fenômeno controlado pela rainha, e pela alimentação fornecida à larva como pode ser observado na Figura 8.

Uma colmeia pode ter em torno de 60000 operárias, uma rainha e 500 zangões aproximadamente.

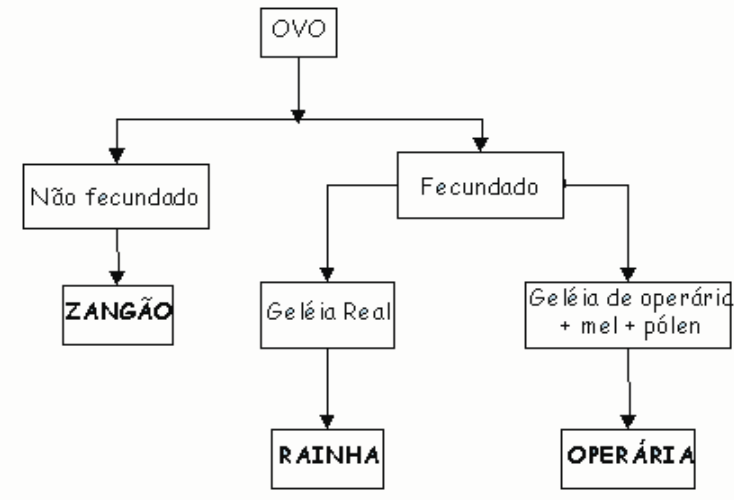

Figura 1: diferenciação do desenvolvimento das abelhas [27]

As abelhas são um exemplo de esforço conjunto de milhares de indivíduos com o objetivo de manter uma estrutura social. Elas desenvolvem uma inteligência coletiva, isto é, o trabalho é individual, mas o objetivo alcançado é coletivo. Isto incrementa o seu desenvolvimento no meio ambiente em que vivem [28]. Mais do que o comportamento individual das abelhas, o comportamento coletivo permite a estes insetos o controle de fenômenos internos e externos, fazendo a contribuição de cada um ser muito maior do que a soma dos comportamentos individuais. Esta é a chave para o sucesso delas [24]. 


\subsection{Requisitos do SIM-Colmeia}

Para alcançar os objetivos educacionais no ensino da dinâmica do crescimento populacional de abelhas, foram levantados os seguintes requisitos gerais para o SIMColmeia:

- Explorar conteúdos do ensino fundamental e do ensino médio para área de domínio da organização de colmeias;

- Gerenciar as plantas em floração;

- Gerenciar as variáveis climáticas: vento, umidade e quantidade chuva, por dia;

- Gerenciar a mudança de dia, isto é, a variação do tempo ao longo da simulação;

- Atualizar os recursos da colmeia;

- Calcular o número de abelhas diariamente;

- Gerenciar a coleta de néctar e pólen;

- Gerenciar o crescimento autônomo da colmeia;

- Utilizar Realidade Virtual para criar um jogo e tornar o ambiente mais lúdico;

Os seguintes requisitos específicos foram identificados para atender o ambiente de simulação:

- Utilizar agentes para executar as tarefas do sistema de forma autônoma;

- Utilizar uma base de dados reais para configuração do ambiente;

- Possibilitar configuração de dados iniciais;

- Possibilitar as configurações passo a passo em interfaces independentes;

- Mostrar resultados numéricos através de gráficos;

- Salvar gráficos de crescimento para posterior comparação;

- Integrar todas as tecnologias envolvidas no desenvolvimento em um único ambiente;

- Oferecer arquivos de ajuda em todas as Interfaces.

\subsection{Modelagem}

Na modelagem do SIM-Colmeia utilizamos a metodologia MaSE (Multi-Agent System Engineering). Ela é aplicada para a modelagem de sistemas Multiagentes e compreende duas fases principais Análise e Design [23]. A fase de análise define as metas, os caos de uso, os papéis e as tarefas de cada agente. Na fase de design são criadas as classes de agentes e as conversações entre eles.

Com base nos requisitos e restrições do domínio do problema, as metas foram definidas:

$=>1-$ Simulação de comportamento de colmeia

$=>1.1-$ Gerenciamento da colmeia

$=>1.1 .1$ - Avaliação da Necessidade de Recursos

=>1.1.1.1 - Avaliação de Necessidade de Expansão da colmeia

$=>1 \cdot 1 \cdot 1 \cdot 1.1-$ Criação de Novas Abelhas

$$
\begin{gathered}
=>1.1 .1 .1 .2-\text { Criação de Novas Células } \\
=>1.1 .1 .1 .3-\text { Avaliação de Necessidade de } \\
\quad \text { Pólen } \\
=>1.1 .1 .1 .4-\text { Avaliação de Necessidade de } \\
\quad \text { Néctar } \\
=>1.1 .1 .1 .5-\text { Avaliação de Necessidade de } \\
\quad \text { Criação de Abelhas } \\
=>1.1 .1 .2-\text { Busca por Campos de Flores } \\
=>1.1 .1 .2 .1-\text { Aliciamento de Abelhas } \\
=>1.1 .2-\text { Promoção de abelhas } \\
=>1.1 .2 .1-\quad \text { Promoção de larvas em } \\
\quad \text { Abelhas Jovens } \\
=>1.1 .2 .2-\text { Promoção de Abelhas Jovens } \\
\quad \text { em Abelhas Campeiras } \\
=>1.1 .3-\text { Eliminação de Abelhas } \\
=>1.1 .4-\text { Produção e Estocagem } \\
=>1.2-\text { Inicialização de Campos de Flores } \\
=>1.2 .1-\text { Floração } \\
=>1.2 .2-\text { Atualização de Recursos }
\end{gathered}
$$

Após a definição das metas, o próximo passo foi definir os casos de uso para que as metas fossem satisfeitas.

Para os casos de uso definidos foram construídos os respectivos diagrama de sequência onde são representadas as interações entre os papéis dos agentes. Os papéis e suas tarefas foram identificadas no Diagrama de Papéis e Diagrama de Tarefas Concorrentes.

Na fase de Design, foi especificado o comportamento do Sim-Colmeia e como este deve ser construído. Assim, na simulação proposta, definimos as classes de agentes (Figura 2) e as respectivas interações entre si.

\subsection{Modelagem Matemática}

A base para os cálculos numéricos realizados pela simulação computacional gerou uma exaustiva busca por trabalhos que fornecessem fundamentação matemática sólida. As pesquisas levaram em consideração dados numéricos de pesquisas de campos realizadas por longos períodos em colmeias. Estes trabalhos originaram tabelas que mostram matematicamente, o comportamento forrageiro das abelhas campeiras.

Para o cálculo da curva de crescimento populacional das abelhas, foi utilizado um modelo quantitativo da dinâmica populacional de abelhas [29]. Neste modelo matemático os ovos de desenvolvem até atingir a fase de pupa. Desta, passam a abelhas jovens, que realizam tarefas na colmeia. Posteriormente passam a abelhas forrageiras e morrem como visualizado na Figura 3. Nesta figura não foram considerados os machos, nem a taxa de mortalidade de abelhas na colmeia.

A postura de ovos é influenciada pelo tamanho da colmeia [29]. A quantidade de abelhas forrageiras influ- 
encia a taxa com que as abelhas que realizam atividades na colmeia passam a forrageiras, processo chamado de inibição social. Dessa forma, qualquer fator que afete as abelhas forrageiras pode lançar precocemente abelhas jovens para essa atividade, provocando um decréscimo na população de abelhas. Além disso, a falta de alimentos suficientes para todos os indivíduos da colmeia pode elevar a taxa de mortalidade das abelhas forrageiras provocando, em longo prazo, o colapso da colmeia.

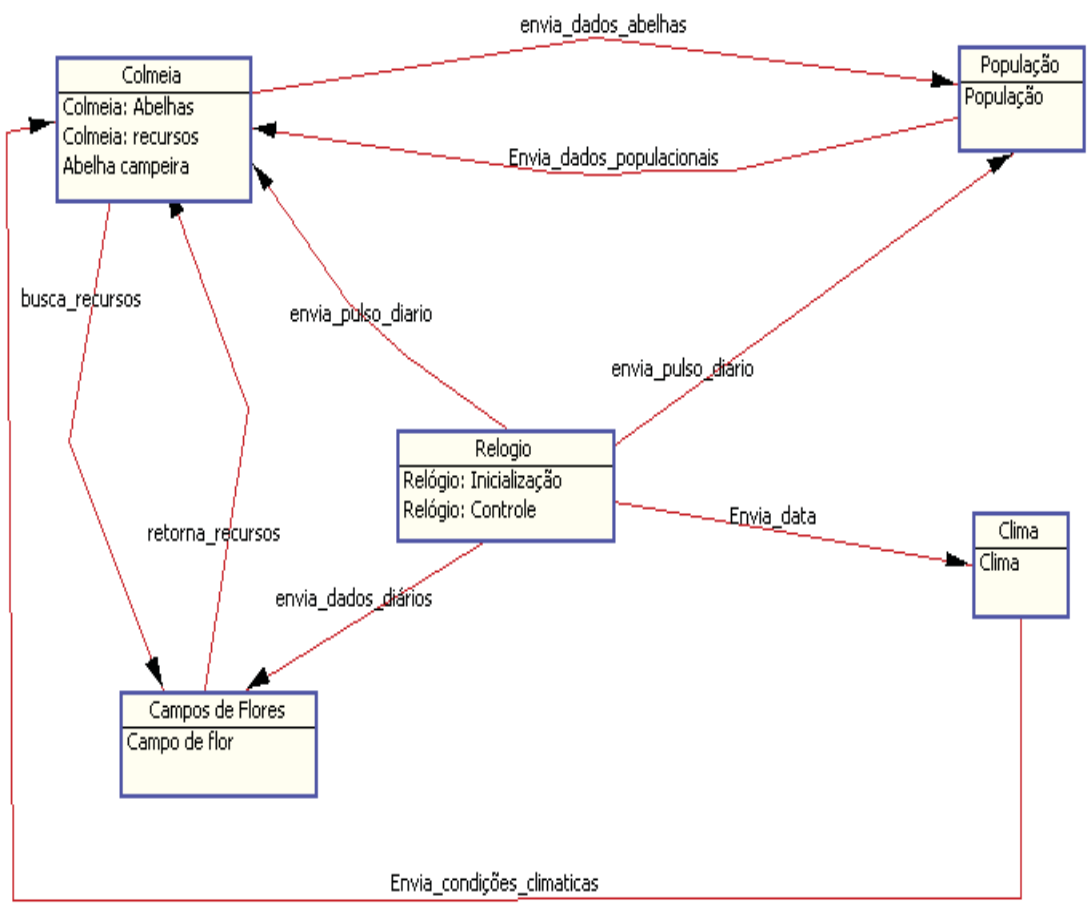

Figura 2: Classes de Agentes

Trabalhos de campo, dentre os quais se destaca o de Khoury et al. [29], comprovam que a longevidade das abelhas forrageiras é um fator importante para a manutenção do equilíbrio coletivo.

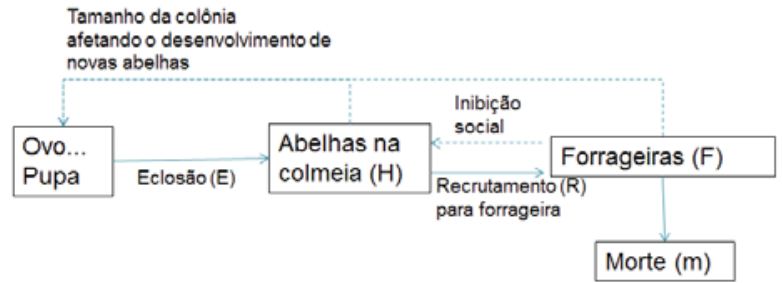

Figura 3: Dinâmica populacional da colmeia, adaptado de Khoury et al, [29].

Khoury et al. [29] representa por equações diferenciais a variação do número de abelhas em atividade na colmeia (1) e a variação do número de abelhas forrageiras (2), ao longo do tempo em dias.

$$
\frac{d H}{d t}=\mathrm{E}(\mathrm{H}, \mathrm{F})-\mathrm{HR}(\mathrm{H}, \mathrm{F})
$$

$\frac{d F}{d t}=\mathrm{HR}(\mathrm{H}, \mathrm{F})-\mathrm{mF}(2)$

$\mathrm{H}$ - Abelhas com atividade na colmeia

$\mathrm{F}$ - Abelhas forrageiras

$\mathrm{m}$ - taxa de mortalidade de abelhas forrageiras

$\mathrm{E}(\mathrm{H}, \mathrm{F})$ - Taxa de eclosões na colmeia

$\mathrm{R}(\mathrm{H}, \mathrm{F})$ - Taxa de recrutamento de abelhas para coleta de recursos

A taxa com que novas abelhas se desenvolvem na colmeia é dada pela função:

$$
E(H, F)=L\left(\frac{H+F}{w+H+F}\right)
$$

L - Número de ovos postos pela abelha rainha w - Taxa em que E(H,F) se aproxima de L

A taxa de recrutamento é dada pela função:

$$
R(H, F)=\propto-\delta\left(\frac{F}{H+F}\right)
$$

$\alpha$ - Taxa máxima de mudança de abelhas para forrageira 
$\delta\left(\frac{F}{H+F}\right)$ - Inibição da mudança para forrageira

As duas funções utilizadas no modelo definem a taxa com que as abelhas se desenvolvem e passam a exercer atividades na colmeia (3) e a taxa com que estas abelhas passam a atividade forrageira (4). Como pode ser observado na equação 3 , a taxa de desenvolvimento de novas abelhas tende a L quando o número total de abelhas é grande $(\mathrm{H}+\mathrm{F})$. Na equação 4 , é observado que a redução do número de forrageiras $(\mathrm{F})$, que pode se dar por aumento da taxa de mortalidade, faz com que a taxa de passagem das abelhas para a atividade forrageira se torne máxima. Isto lança abelhas precocemente na atividade de coleta de nutrientes e pode levar a colmeia ao colapso.

Dados do modelo foram comparados com dados experimentais e mostram resultados equivalentes para o tempo de vida e a idade com que as abelhas forrageiras iniciam o trabalho de coleta de néctar e pólen. Os resultados são apresentados na tabela 2 .

\begin{tabular}{|c|c|c|c|c|c|}
\hline \multirow[t]{2}{*}{ Colônia } & \multirow[t]{2}{*}{$\begin{array}{l}\text { Índice } \\
\text { Morte }\end{array}$} & \multicolumn{2}{|c|}{$\begin{array}{l}\text { Idade Média da Abelha } \\
\text { se tornar Forrageira }\end{array}$} & \multicolumn{2}{|c|}{$\begin{array}{l}\text { Tempo de Vida } \\
\text { de uma Abelha }\end{array}$} \\
\hline & & Observado & Modelado & Observado & Modelado \\
\hline 1 (Grande) & 0,133 & 18,6 & 19,4 & 22,8 & 26,9 \\
\hline 2 (Grande) & 0,154 & 18,4 & 17,7 & 22,3 & 24,2 \\
\hline 3 (Pequena) & 0,149 & 23,8 & 17,6 & 26,6 & 24,3 \\
\hline 4 (Pequena) & 0,114 & 22,2 & 20,4 & 26,4 & 29,2 \\
\hline
\end{tabular}

Tabela 2 : Comparação de dados experimentais e resultados do modelo [29].

O balanço energético da colmeia foi fundamentado pelo trabalho de Southwick e Pimentel [30]. Eles quantificaram a coleta de pólen e néctar e a produção de mel e cera por abelhas de uma colmeia. Uma colmeia com aproximadamente 50000 abelhas produz, em média, 125 $\mathrm{Kg}$ de mel. Para isso, são necessários cerca de $250 \mathrm{Kg}$ de Néctar por ano. Para o pólen, elas coletam cerca de $25 \mathrm{~kg}$ por ano. Em média, esta colmeia consume cerca $90 \%$ do mel produzido para executar suas atividades. Dessa forma, cerca de $15 \mathrm{Kg}$ de mel são armazenados em uma colmeia não gerenciada, isto é, que esteja em um ambiente selvagem.

Em média uma abelha carrega uma carga de néctar de cerca de $40 \mathrm{mg}$. Já para o pólen, elas carregam cerca de $20 \mathrm{mg}$ [30].

Entretanto, os cálculos apresentados sobre o balanço energético não levam em consideração as influências climáticas e possíveis sazonalidades nas florações. Assim, tornou-se necessária a busca por trabalhos que embasassem a influência destes fatores.

O departamento de Ecologia do Instituto de Biologia da USP possui um Laboratório de abelhas, que disponibiliza uma tabela com o período de floração de plantas visitadas pelas abelhas "Apis melífera" [31]. Neste caso, também são disponibilizados o nome científico e nome popular de cada planta. A partir da escolha de 95 plantas, foi criado um banco de dados que é acessado pelo sistema para obter informações sobre as plantas em floração, em um determinado período de tempo.

Em um mês específico, uma planta pode estar ou não em período de floração. Caso esteja em floração, ela pode estar no pico da floração ou não. Além disso, a planta pode ter o recurso néctar ou pólen, ou ainda, ambos.

Além da floração, que fornece os recursos que garantem o equilíbrio energético da colmeia, os fatores climáticos afetam a atividade de voo das abelhas. Pesquisas mostram a influência no número de voos de abelhas com a variação da velocidade do vento. Ele é considerado um fator restritivo em muitas pesquisas [32]. Gráficos podem ser gerados mostrando o comportamento de voo de abelhas em função da velocidade do vento e a estação do ano. Um destes gráficos que foi utilizado como base para este trabalho é visto no Gráfico 1.

Outro fator de influência da atividade de voo é a precipitação pluviométrica [33]. A queda do número dos voos pode ser estudada em função de vários fatores: frequência, duração, hora em que ocorre e intensidade de chuva.

A umidade relativa do ar também influencia a atividade de forrageamento de abelhas. Umidade entre $43,13 \%$ e $92,70 \%$ foram ideais para coleta de néctar. E entre $45,00 \%$ e $89,50 \%$ foi a faixa ideal para pólen [31].

Muitos são os fatores que agem influenciando as atividades de uma colmeia. Há relações importantes entre todos os fatores climáticos citados, aumentando em muito a complexidade do modelo proposto. Cada fator climático observado possui um campo de análise muito grande. Por exemplo, a velocidade do vento tem uma influência diferente quando associada com a direção do vento e o tamanho da abelha. Assim, a simulação não leva em consideração essas inter-relações entre alguns desses fatores.

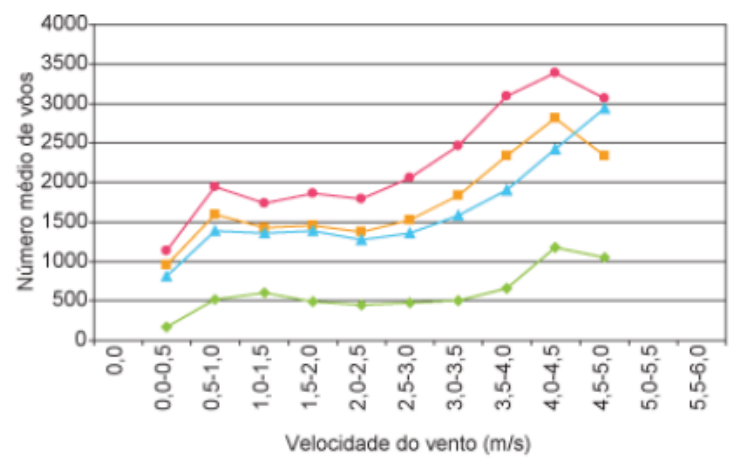

Gráfico 1 : Gráfico da atividade de voo de abelhas em função da velocidade do vento no outono. As cores indicam colmeias de tamanhos diferentes [33]. 
Os dados climáticos diários foram obtidos dos boletins meteorológicos do Instituto de Astronomia, Geofísica e Ciências Atmosféricas da Universidade de São Paulo. Eles estão divididos pelas horas do dia, sendo de interesse deste trabalho a umidade, a velocidade do vento e a precipitação pluviométrica no horário de $7 \mathrm{~h}$ às $18 \mathrm{~h}$ [32], [33].

\section{Protótipo SIM-Colmeia}

Na construção do protótipo do Sim-Colmeia o Framework utilizado foi o Java Agent Development Framework-JADE [34], que possui várias bibliotecas para utilização em sistemas desenvolvidos na linguagem JAVA. O JADE constitui uma camada intermediária para a criação e gerenciamento de agentes. Pode ser facilmente integrado com camadas de mais alto nível de abstração.

Como IDE Java, para o desenvolvimento dos agentes e do sistema, foi escolhido o NetBeans [35]. Este ambiente possui fácil integração com JADE.

$\mathrm{Na}$ figura 4, é mostrada a janela inicial do processo de simulação. Nela, deve ser escolhido o número de campos de flores. Os tipos de campos poderão ser determinados na tela seguinte (Figura 5).

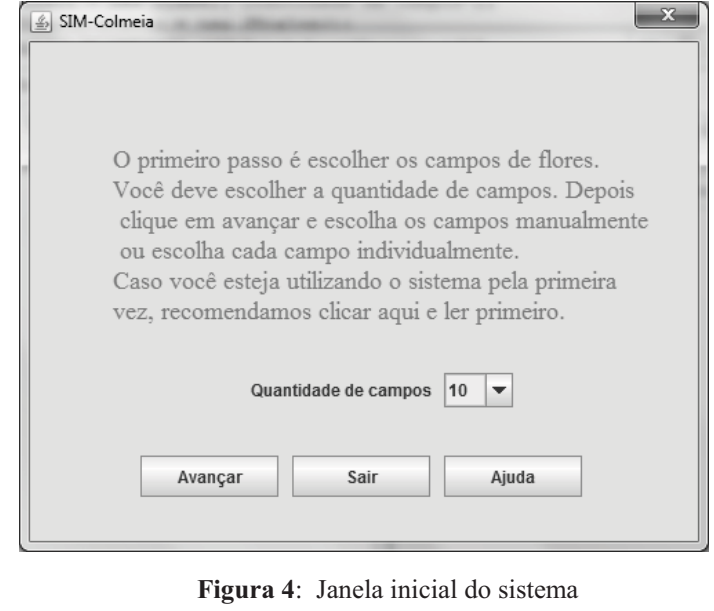

Ao avançar no sistema, o usuário passa para a tela de escolha dos campos de flores, onde pode optar por escolher, ou deixar que o sistema preencha os campos automaticamente. A Interface oferece ao usuário todos os campos de flores com o tipo de recurso, os meses de florada e a sua intensidade. À medida que os campos vão sendo escolhidos, uma tabela anual de floradas vai sendo montada para que o usuário possa conferir como está a sazonalidade das floradas naquele período. Ainda é possível ao usuário eliminar um campo e escolher um novo para o seu lugar. Nesta tela existe uma opção de menu para ajudar o usuário, caso ele tenha dificuldades para o preenchimento.

Ao terminar as escolhas dos campos, o usuário passa para uma tela onde ele pode alterar as configurações iniciais do sistema. São escolhidos o número inicial de abelhas, a taxa de mortalidade e postura de ovos pela abelha rainha, além da velocidade da simulação. 


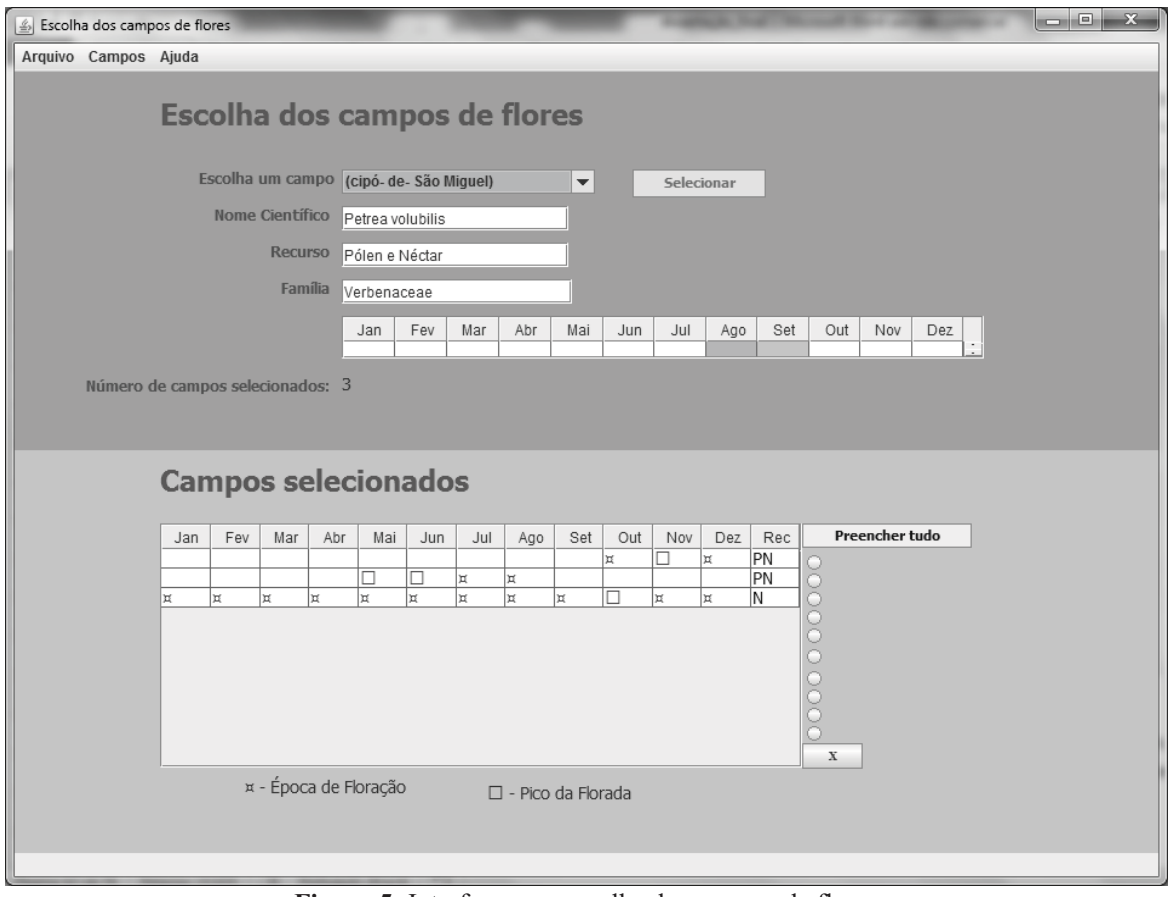

Figura 5: Interface para escolha dos campos de flores

Nesta tela, o usuário tem a opção de ir para a tela de configurações climáticas. Caso escolha esta opção, uma nova janela aparece, como mostrado na Figura 6. A configuração possível é a fixação de um valor para uma variante climática durante todo um mês. Dessa forma, o sistema ignora os dados meteorológicos armazenados relativos aquele mês, substituindo pelos valores escolhidos pelo usuário.

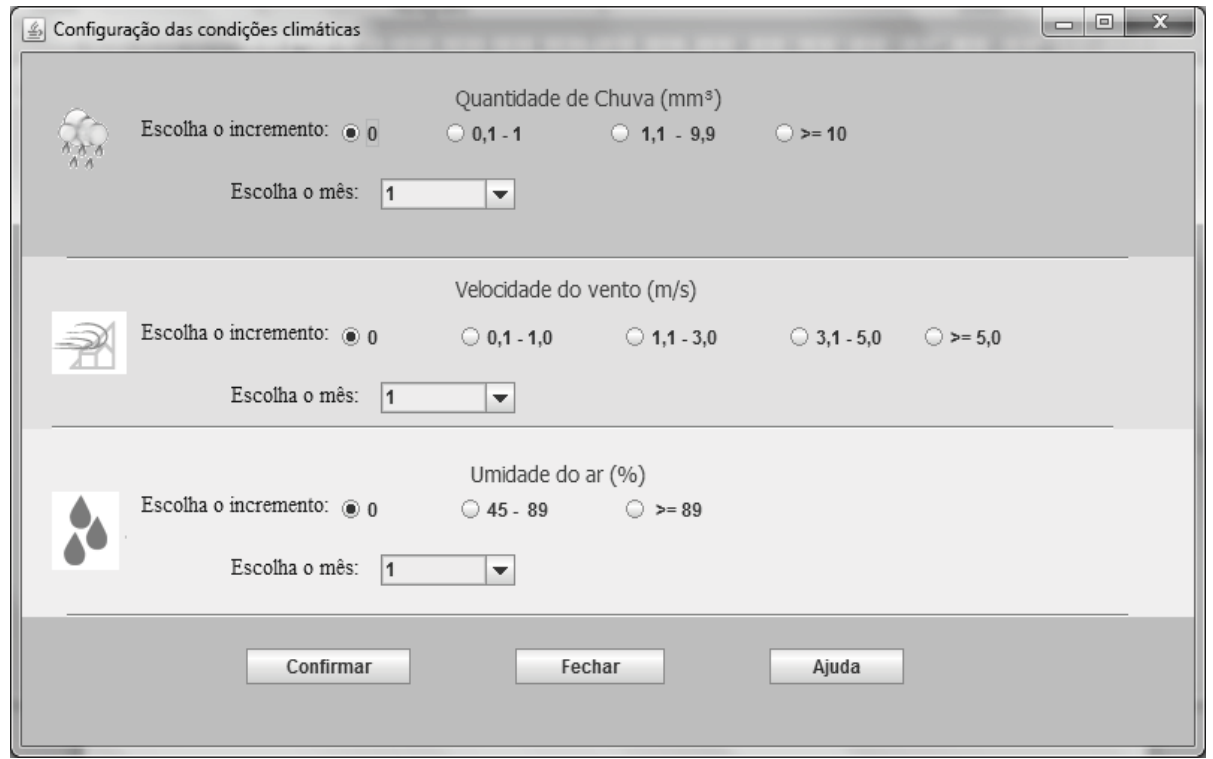

Figura 6: Interface para definição de condições climáticas

Com estas duas configurações definidas, o usuário pode iniciar a simulação. A tela de simulação apresenta informações sobre o tempo decorrido, a quantidade de mel armazenado, o número de abelhas na colmeia, a postura de ovos pela abelha rainha, a taxa de mortalidade, os campos em floração e abelhas forrageiras (Figura 7). 
O usuário pode pausar a simulação a qualquer momento, sem perda de dados ao retornar, caso queira verificar algum dos dados disponíveis nos menus.

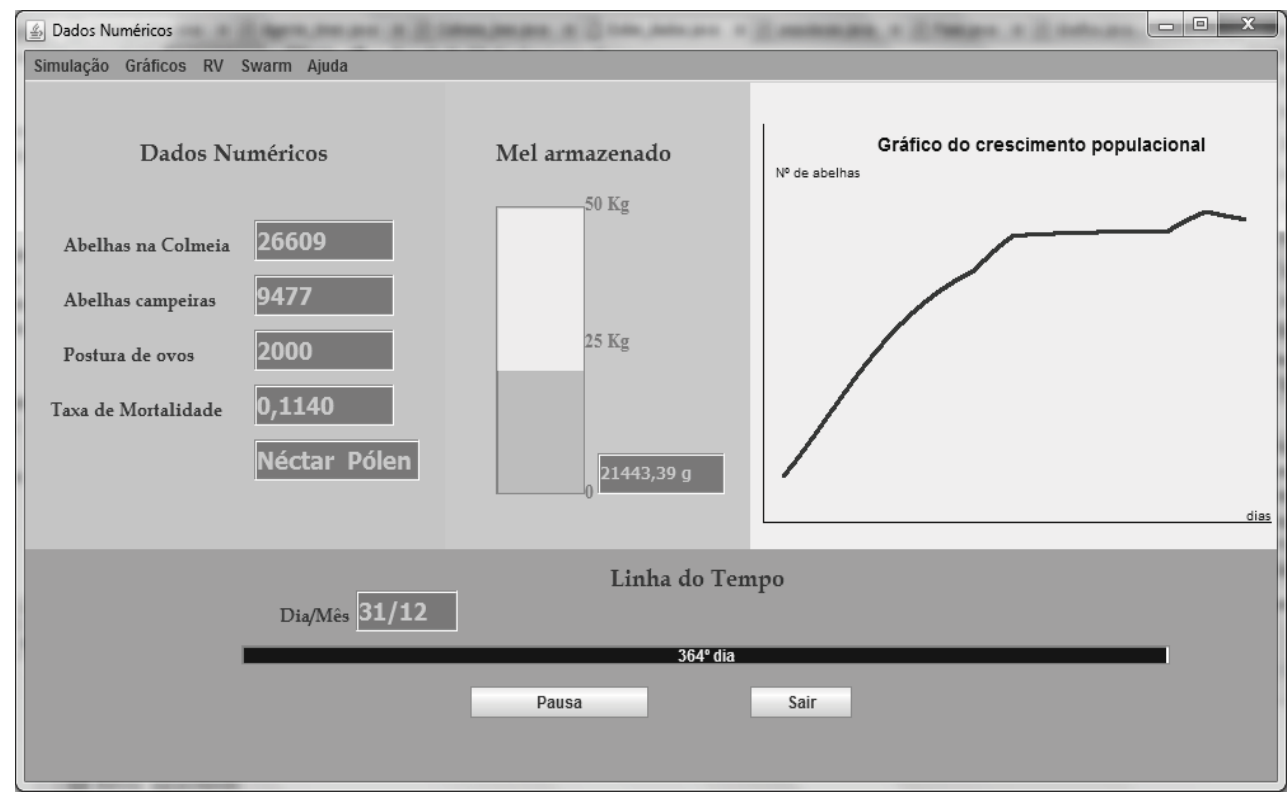

Figura 7: Interface de simulação

Os gráficos oferecem uma forma de visualizar as informações do que está acontecendo ao longo do tempo de forma detalhada. Eles podem ser gerados para um determinado mês ou acompanhar a evolução ao longo do tempo. Na Figura 8 é visualizado o gráfico do crescimento populacional em função do tempo.

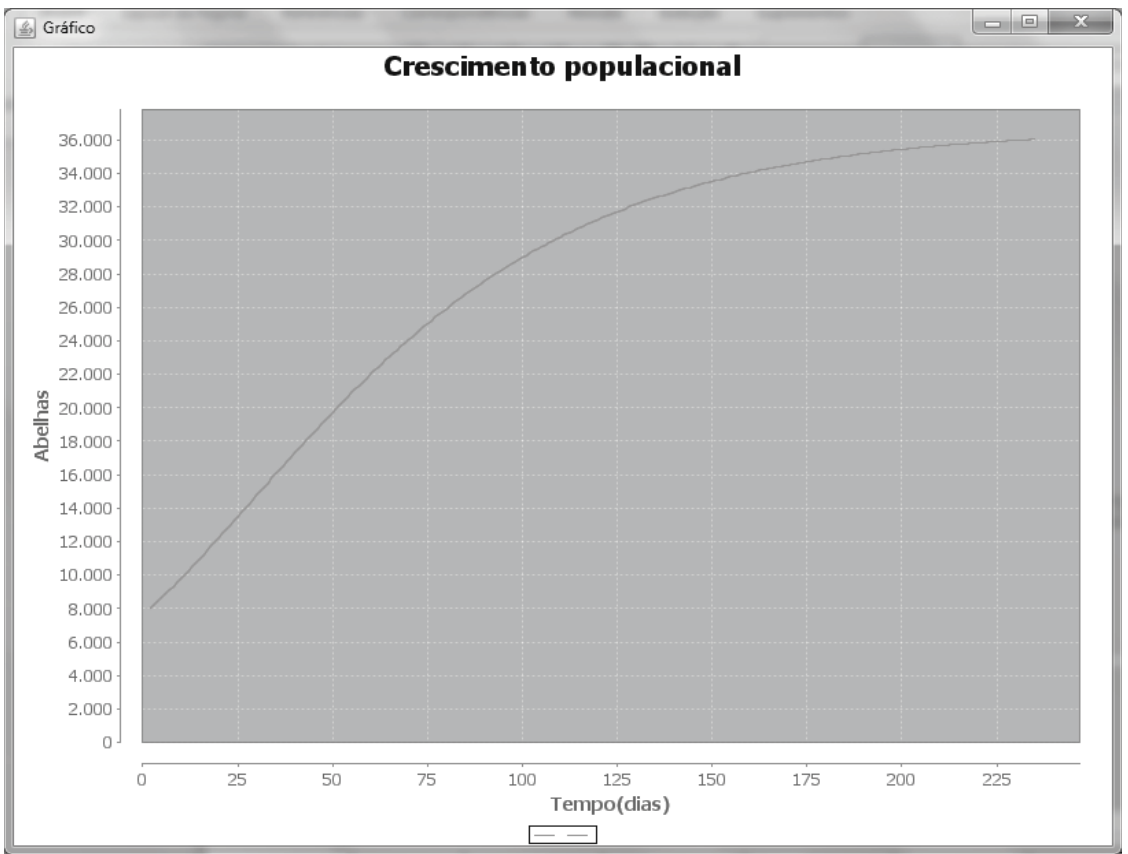

Figura 8: Gráfico do Crescimento populacional ao longo do tempo 
Outra possibilidade da opção de gráficos é a comparação do gráfico de crescimento populacional da simulação em curso com dois gráficos salvos anteriormente. É possível salvar até cinco gráficos e compara-los (Figura 9).

\section{Testes de verificação do SIM- Colmeia}

Visando analisar as diferentes possibilidades de exploração do SIM-Colmeia, foram realizados algumas simulações, com variação de parâmetros. Os dados obtidos no SIM-Colmeia foram comparados com os resultados obtidos na literatura consultada.

Uma população possui curva de crescimento denominada sigmóide, resultante de uma ação de fatores ambientais limitantes [36]. Nestas curvas o crescimento inicial de uma nova população é rápido, atingindo um ponto de equilíbrio, que é dependente da resistência ambiental sobre a população. Assim, variando os fatores ambientais, tais como, clima e alimentação, obteremos curvas diferentes.

A população cresce até um fator $\mathrm{K}$, que representa $\mathrm{o}$ número de indivíduos de uma população, que os recursos ambientais podem manter [37]. O fator $\mathrm{K}$ representa uma faixa de valores, sem tendência de aumentar ou diminuir, pois ao longo do tempo as populações sofrem maior ou menor pressão ambiental.

O objetivo deste teste foi verificar o formato das curvas de crescimento e comparar curvas diferentes, ou seja, com parâmetros limitantes ao longo de diferentes espaços de tempo, visando verificar se possuem fatores $\mathrm{K}$ diferenciados. Para isso, foram comparados três casos, descritos a seguir:

Caso 1: Condições climáticas padrão e campos de flores com picos nos meses 5, 8,11 e 12 .

Caso 2: Condições climáticas padrão e campos de flores com pico de floração no mês 5 .

Caso 3: Configuração das condições climáticas para vento de $5,0 \mathrm{~m} / \mathrm{s}$ no mês 3 , chuva de $3,0 \mathrm{~mm}^{3}$ no mês 6 e umidade de $89 \%$ no mês 10 . Campos de flores com pico de floração no mês oito.

O resultado pode ser observado na Figura 9.

Como esperado, as três populações que enfrentaram limitações do ambiente diferentes ao longo do tempo apresentaram ponto de equilíbrios diferentes. Além disso, o formato da curva para os três casos foi o mesmo.

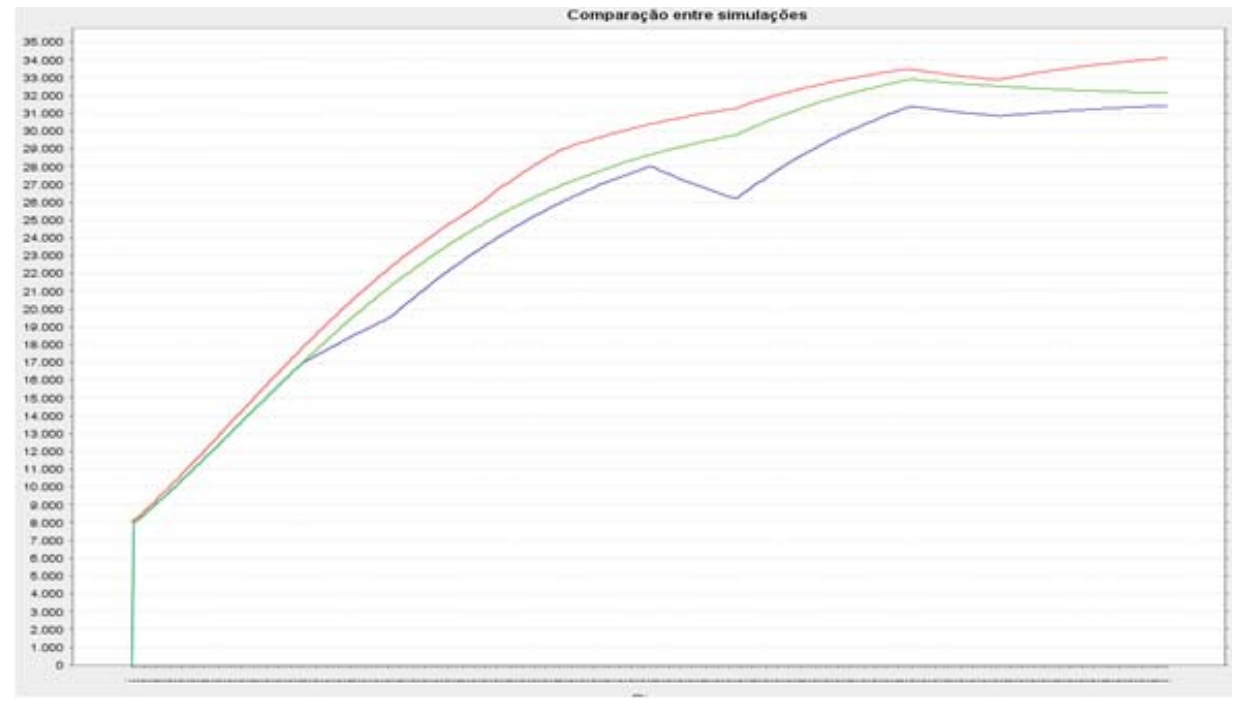

Figura 9 : Comparação entre curvas de crescimento para os casos 1, 2 e 3.

Nos testes realizados com a simulação computacional do crescimento populacional foi possível observar que os dados obtidos se encontram dentro das expectativas. $\mathrm{O}$ objetivo destes testes era confirmar que os resultados obtidos se comportavam como esperado quando as configurações iniciais eram alteradas. Com relação ao formato do gráfico, o comportamento foi confirmado com a alte- ração do fator $\mathrm{K}$, isto é, do ponto de equilíbrio do crescimento, e a manutenção do formato do gráfico nos três casos.

Por fim, os testes realizados para verificar os resultados numéricos e o balanço energético, ou seja, a produção de mel mostraram que, como esperado, à medida que existe mais disponibilidade de alimento, isto é, com mais 
meses em que as plantas estão em pico de florada, a produção de mel aumenta, assim como o número total de abelhas. No caso em que durante um mês não houve disponibilidade de recurso floral, houve o colapso da colmeia. Quando a disponibilidade de alimento é inexistente por um longo período as abelhas migram para outro local visando fundar uma nova colmeia. E esse resultado foi obtido pelo sistema, mostrando que as simulações realizadas pelo SIM-Colmeia estão bem próximas dos fatos reais.

\section{Conclusões}

A utilização de simulações no ensino de Biologia se constitui em uma potente ferramenta para o processo ensino-aprendizagem. A Biologia é uma área do conhecimento onde a formulação de hipóteses e o processo de testar estas hipóteses é fundamental para sua compreensão. A simulação permite a alteração de parâmetros que regem os sistemas biológicos, mostrando comportamentos difíceis de serem observados no mundo real e ampliando as possibilidades de aprendizagem de comportamentos complexos.

A integração de diferentes tecnologias para desenvolver o SIM-Colmeia foi o maior desafio enfrentado no desenvolvimento deste trabalho, já que não tivemos acesso a trabalhos similares. Contudo, o resultado final corroborou a perfeita integração entre as tecnologias utilizadas. Um aspecto que contribuiu fortemente para esse bom resultado foi a linguagem de programação JAVA, que facilitou essa integração.

Trabalhar de forma interdisciplinar agregou um alto valor para o trabalho, já que vários desafios devem ser superados e incluem aspectos teóricos e técnicos. A área de Biologia é rica de conteúdos, principalmente aqueles relacionados ao meio ambiente. Isto exige um trabalho atento de pesquisa e validação de dados reais coletados e torna o trabalho bastante interessante e atual, levando a área de Ciências Computacionais a estar mais próxima de outras áreas do conhecimento. Por outro lado, contribuir para a área educacional é sempre importante, já que existe carência de ferramentas de simulação que apóiem o trabalho docente e o processo de aprendizagem. Especificamente, para a área de Biologia não existem muitos softwares que ofereçam materiais diversificados para o aprendizado de conceitos complexos de serem observados no mundo real. Os que existem, não oferecem muitas opções para se trabalhar com diferentes variáveis reais. Naturalmente, são de propósito geral, podendo ser utilizados em diversas áreas.

A inclusão de um módulo apoiado na tecnologia de Realidade Virtual enriquecerá o ambiente, pois oferecerá uma forma lúdica para entender o que é a atividade forrageira de uma abelha, apoiando o aprendizado de jovens e crianças. Os aspectos envolvidos no crescimento de uma colmeia, a necessidade de coletar néctar para produzir mel e garantir o fornecimento de energia para toda a colmeia, será explorado em um módulo contendo um jogo $3 \mathrm{D}$, tornando a percepção dos fatos mais clara e mais lúdica, estimulando a interação dos alunos com o tema.

Na área de simulação, ficou evidente a necessidade de modelos matemáticos, que descrevam exatamente as atividades a serem simuladas. Outro aspecto, que colaborou para o sucesso deste trabalho foi a existência de bases de dados reais, que armazenam diferentes fatores climáticos de várias regiões do país.

Os testes foram de grande importância para o desenvolvimento do protótipo, pois mostrou que os resultados gráficos e numéricos da simulação para configurações iniciais diferentes são os esperados pela literatura da área.

Em trabalhos futuros, o número de variáveis que afetam a população pode ser aumentado na simulação. $\mathrm{O}$ equilíbrio observado em uma colméia, e que garante o sucesso destes insetos, é mantido a partir de uma complexa rede de fatores. Na verdade, a complexidade é maior do que aquela considerada por este trabalho. Vai desde o envelhecimento da abelha rainha, até o ataque de pragas. Um exemplo disso é o parasita Varroa que causa um desequilíbrio na população de abelhas e que pode levá-las ao colapso [38]. Outros aspectos climáticos também podem ser considerados.

Outro ponto que pode ser explorado em um trabalho futuro é o acréscimo de novas configurações climáticas padrões, oferecendo ao usuário a escolha de variadas combinações climáticas.

Com relação aos testes, o principal ponto a ser explorado no futuro é a utilização em um ambiente educacional por alunos do curso de Biologia, visando analisar a sua contribuição para o processo de ensino e aprendizagem nos ensinos fundamental e médio. Dessa forma, será possível avaliar, de forma empírica, o impacto do ambiente no processo de ensino e aprendizagem.

Em relação aos Ambientes de Aprendizagem na área de Biologia, podemos verificar as contribuições deste trabalho. Destacamos a exploração de metodologia formais de modelagem e desenvolvimento dos agentes e a criação de um produto que além de poder contribuir para o processo educacional, traz novas propostas de integração de tecnologias, visando o desenvolvimento de um sistema de simulação com características mais inteligentes.

Nenhum dos ambientes correlatos citados integra tecnologias diferentes. Eles possuem limitações na maneira como exibem os resultados e exploram o conteúdo. Alguns têm como objetivo criar uma simulação, obrigando o usuário a ter um conhecimento maior do processo de criação da simulação. Em outros, a interatividade é baixa, não permitindo a configuração inicial de parâmetros. Dessa forma, se comparado com os trabalhos menciona- 
dos, o protótipo apresentado neste trabalho tem como vantagens trabalhar com dados reais, como o clima e a floração das plantas, bom grau de interatividade e de configuração dos aspectos da simulação e comparação de gráficos simulados.

\section{Referências}

[1] C. S. Bezerra, et al. A utilização de modelos como recursos didáticos no ensino de Biologia para jovens e adultos. III Congresso de Pesquisa e Inovação da Rede Norte e Nordeste de Educação Tecnológica. Fortaleza, CE. 2008.

[2] N. N. Fialho, E. L. M. Matos. A arte de envolver o aluno na aprendizagem de ciências utilizando softwares educacionais. Educar em Revista, n. especial, (2):121-136, 2010.

[3] S. C. M. Fonseca.. Influência de gases inertes no equilíbrio químico: Nuances e simulações computacionais. Dissertação de Mestrado, Universidade do Porto, mar. 2006.

[4] M. H. Mulinari, L. Ferracioli. A utilização da tecnologia no ensino de Biologia: um experimento com um ambiente de modelagem computacional. Revista Brasileira de Ensino de Ciência e Tecnologia, 1(1): 98-115, 2008.

[5] A. S. T. Pereira, F. F. Sampaio. Avitae: desenvolvimento de um ambiente de modelagem computacional para o ensino de Biologia. Ciências \& Cognição, 13(.2): 51-70, 2008.

[6] M. Dorigo. Swarm Intelligence. Springer Verlag, 1(1): 1-2, 2007.

[7] P. A. Filho. Educação e a cultura da informática. Revista Eletrônica de Educação, 2(1): 43-57, 2008.

[8] L. L. Lazzarotto, et al. A educação em ambientes virtuais: proposição de recursos computacionais para aumentar a eficiência do processo ensino-aprendizado. Revista Brasileira de Informática na Educação, 19(2): 42-55, 2011.

[9] L. L. Azevedo, C. S. Menezes, B. C. Magdalena, E. Pontarolo. Ambientes Computacionais Orientados a Agentes para apoio à Aprendizagem Baseada em Simulação. In Anais do XVI Simpósio Brasileiro de Informática na Educação, páginas 52-62, 2005.

[10] L. L. Azevedo, C. S. Menezes. NetPlay: uma ferramenta para construção de modelos de simulação baseado em multiagente. In Anais do XVIII Simpósio Brasileiro de Informática na Educação, páginas 370-381, 2007.

[11] R. K. Lowe. Animation and learning: selective processing of information in dynamic graphics. Learning and Instruction. The Journal of the European Association for Research on Learning and Instruction, 13( 2): 157-176, 2003.

[12] B. Tversky, J. B. Morrison, M. Bétrancourt. Animation: can it facilitate? International Journal of Human-computer Studies, 57(4): 247-262, 2002.

[13] M. S. Miranda, A. R. Arantes, N. Studart. Objetos de Aprendizagem no Ensino de Física: Usando Simulações do PhET. Física na Escola, 11(1): 27-31, 2010.

[14] B. Franck, B. Paula M. B. \& V. Gitirana, Simulação no ensino da matemática: um exemplo com cabri-géomètre para abordar os conceitos de área e perímetro. III Seminário Internacional de Pesquisa em Educação Matemática. 2006.

[15] B. S. Meiguins, M. P. Sousa, L. A. Guedes, M. B. Garcia, B. S. Meiguins, Ambientes Virtuais Tridimensionais para Simulação de Experiências da Física Fundamental. In Anais do Simpósio Brasileiro de Informática na Educação, p. 512514, 2002.

[16] Wallis, J., Chichakly, K., Peters S., \& Richmond B. STELLA ${ }^{\circledR}$ Research software. High Performance Systems, Inc., Hanover, 2001.

[17] J. O. Guterres, M. L. Eichler, J. C. Del Pino, Compreensões de professores sobre o software educativo Carbópolis e sua utilização em diferentes realidades de escola. Revista brasileira de informática na educação, 11(2): 86-99, 2003.

[18] Carl Hayden Bee Research Center, WebBeePop model, United States Department of Agriculture's Agriculture Research Service, disponivel em

http://gears.tucson.ars.ag.gov/beepop/index.html acessado em 10/09/2012.

[19] CSERD (The Computational Science Education Reference Desk), Individual (Agent) Based Modeling with NetLogo A Predator-Prey Example, disponivel em www.shodor.org/media/download $/ /$ refdesk $/ . . . / \mathrm{m}$ odels/.../tutorial.pdf acessado em 10/09/2012.

[20] K. John, Cell Biology Animation, ScienceGraphics, disponivel em http://www.johnkyrk.com/ acessado em 10/09/2012.

[21] M. Dorigo, M. Birattari. Swarm Intelligence. Scholarpedia, 2(9): 14-62, 2007.

[22] A. S. Silva. Modelagem orientada a agentes para simulação de colônias de bactérias. Trabalho final de Graduação. Universidade Estadual do Rio de Janeiro. 2011.

[23] S. A. Deloacht, M. Kumar. Multi-Agent Systems Engineering: An Overview and Case 
Study. IGI Global, Vancouver, 2009.

[24] M. L. Winston. The Biology of the Honey Bee. Harvard University Press,. Cambridge. 1991.

[25] D. Stone. An Introduction to Bee Biology. University Laboratory High School.Illinois. 2005.

[26] J. M. Ramos, N. C. Carvalho. Estudo morfológico e biológico das fases de agentes para simulação de colônias de bactérias. Trabalho final de curso. Universidade Estadual do Rio de Janeiro. 2011.

[27] J. M. Ramos, N. C. Carvalho. Estudo morfológico e biológico das fases de desenvolvimento de Apis melífera. Revista Científica Eletrônica de Engenharia Florestal, 4(10), 2007.

[28] L. A. G. Andrade, Cunha, B. Cláudio. Algoritmo de colônia artificial de abelhas para um problema de clusterização capacitado. In Anais do XLIII Simpósio Brasileiro de Pesquisa Operacional. Ubatuba. SP. 2010.

[29] D. S. Khoury, M. R. Myerscough, A. B. Barron. A Quantitative Model of HoneyBee Colony Population Dynamics. PLoS ONE, 6(4): 1-6, 2011.

[30] E. E. Southwick, D. Pimentel. Energy Efficiency of Honey Production by Bees. BioScience, 31(10): 730-732, 1991.
[31] D. T. Malerbo-Souza, F. A. S. Silva. Comportamento forrageiro da abelha africanizada Apis mellifera no decorrer do ano. Acta Scientiarium Animal Sciences, 33(2): 183-190, 2011.

[32] S. D. Hilário et al. Efeito do vento sobre a atividade de vôo de Plebeia remota. Revista Biota Neotropica, 7(3): 225-232, 2007.

[33] S. D. Hilário et al. Efeito da preciptação pluviométrica sobre a atividade de vôo de Plebeia remota. Revista Biota Neotropica, 7(3): 135143, 2007.

[34] JADE. Framework JADE. Disponível em http://jade.tilab.com acessado em 01/09/2012.

[35] Netbeans. Disponível em http://netbeans.org acessado em 12/09/2012.

[36] E. P. Odum, G. W. Barret. Fundamentos de ecologia. Thomson Learning, São Paulo. 2007.

[37] N. Peroni, M. I. M. Hernándes. Ecologia de populações e comunidades. CCB/EAD/UFSC, Florianópolis. 2011.

[38] Winston, Mark L. The Biology of the Honey Bee. Harvard University Press. Cambridge: USA. 1991. 